\title{
Diverse Morbidity and Mortality Among Infants Treated with Venoarterial Extracorporeal Membrane Oxygenation
}

Sigrid Bairdain ${ }^{1}$, Peter Betit ${ }^{2}$, Nancy Craig ${ }^{2}$, Kimberlee Gauvreau ${ }^{3}$, Peter Rycus ${ }^{4}$, Jay M. Wilson $^{5}$, Ravi Thiagarajan ${ }^{3}$

1. Department of Surgery, Boston Children's Hospital 2. Department of Respiratory Therapy, Boston Children's Hospital 3. Department of Cardiology, Boston Children's Hospital 4. ELSO Executive administrator, ELSO 5. Department of Pediatric Surgery, Boston Children's Hospital

$\square$ Corresponding author: Sigrid Bairdain, sbairda@yahoo.com

Disclosures can be found in Additional Information at the end of the article

\section{Abstract}

Background: Venoarterial extracorporeal membrane oxygenation (VA-ECMO) is utilized for cardiopulmonary failure. We aimed to qualify and quantify the predictors of morbidity and mortality in infants requiring VA-ECMO.

Methods: Data was collected from 170 centers participating in the extracorporeal life support organization (ELSO) registry. Relationships between in-hospital mortality and risk factors were assessed using logistic regression. Survival was defined as being discharged from the hospital.

Results: Six hundred and sixty-two eligible records were reviewed. Mortality occurred in 303 (46\%) infants. Congenital diaphragmatic hernia patients (OR=3.83, 95\% CI 1.96-7.49, p<0.001), cardiac failure with associated shock $(\mathrm{OR}=2.90,95 \% \mathrm{CI} 1.46-5.77, \mathrm{p}=0.002)$, and pulmonary failure including respiratory distress syndrome $(\mathrm{OR}=4.06,95 \% \mathrm{CI} 1.72-9.58, \mathrm{p}=0.001)$ had the highest odds of mortality in this cohort. Birth weight $(\mathrm{BW})<3 \mathrm{~kg}(\mathrm{OR}=1.83,95 \%$ CI 1.21-2.78, $\mathrm{p}=0.004)$, E-CPR (OR=3.35, 95\% CI 1.57-7.15, $\mathrm{p}=0.002)$, hemofiltration (OR=2.04, 95\% CI 1.32$3.16, \mathrm{p}=0.001)$, and dialysis $(\mathrm{OR}=6.13,95 \% \mathrm{CI} 1.70-22.1, \mathrm{p}<0.001)$ were all independent predictors of mortality.

Conclusion: Infants requiring VA-ECMO experience diverse sequelae and their mortality are high.

Received 01/10/2015 Review began 01/11/2015 Review ended 03/28/2015 Published 04/07/2015

\section{(C) Copyright 2015}

Bairdain et al. This is an open access article distributed under the terms of the Creative Commons Attribution License CC-BY 3.0., which permits unrestricted use, distribution, and reproduction in any medium, provided the original author and source are credited.
Categories: Pediatric Surgery, Cardiac/Thoracic/Vascular Surgery, Quality Improvement Keywords: venoarterial extracorporeal membrane oxygenation (va-ecmo), infants, mortality, morbidity

\section{Introduction}

Extracorporeal membrane oxygenation (ECMO) may be a life-saving modality for pediatric patients with either severe cardiac disease or respiratory failure [1]. However, these patients continue to represent a potentially very critical sub-cohort of intensive care unit patients, and their overall survival is still very poor [2]. According to the Extracorporeal Membrane Support Registry Report from 2012, approximately 13,000 patients have been treated with survival to discharge rates of $40 \%, 49 \%$, and $39 \%$ for neonates, pediatric, and adults, respectively [2].

Since its inception, extracorporeal life support has been used as a modified form of 
cardiopulmonary bypass and has become an accepted therapeutic modality despite an ever increasing severely-ill cohort of patients [3]. Venoarterial extracorporeal membrane oxygenation (VA-ECMO) is a specific type of extracorporeal membrane life support. VA-ECMO differs from venovenous extracorporeal membrane oxygenation (VV-ECMO), another form of extracorporeal membrane life support, as VA-ECMO is utilized specifically for both hemodynamic and respiratory support; VV-ECMO is utilized primarily for respiratory support [4]. Physiological effects of VA-ECMO differ from VV-ECMO as VA-ECMO results in a mixture of pulsatile and non-pulsatile flow to multiple organ systems, require anticoagulation, and cannot be maintained indefinitely [4-5].

As aforementioned, different underlying etiologies require the use of VA-ECMO; however, common morbidities associated with VA-ECMO range from primary mechanical, renal, lung, and neurological, as well as neurodevelopment concerns [6-7]. There are numerous reports suggesting that underlying etiology, factors preceding, as well as congruent with the initiation of VA-ECMO are important predictors of morbidity and mortality. In particular, more recent reports by Zwiers, et al. (2012) and Askenazi, et al. (2011) have paid special attention to the relationship between the role of fluid overload and acute kidney injury as independent predictors of morbidity and mortality in cohorts of patients primarily on VA-ECMO [8-9]. Therefore, predicting survivability in this cohort, while weighing the constant morbidity and mortality risk in these complex patients, is a constant challenge for the treatment team. Using the extracorporeal life support organization (ELSO) registry data for a one-year time period, the aim of this study was to quantify and qualify the morbidity and mortality of a cohort of infants ages $0-1$ years requiring VA-ECMO.

\section{Materials And Methods}

\section{Population}

Following IRB approval (IRB \#00010390) from the Boston Children's Institutional Review Board, infants aged 0-1 years that required VA-ECMO for a one-year period were retrospectively reviewed from the Extracorporeal Life Support Organization (ELSO) registry. The ELSO registry collects data on ECMO procedures performed and is prospectively collected from patients admitted to over 170 centers participating in the registry. The centers included are voluntary members. The ELSO dataset is based off either ICD-9 codes and/or CPT codes for procedures. It does not include specific dates, indications for initiation of specific therapies, or relationship to surgeries.

Criteria to initiate VA-ECMO and placement of cannulas (centrally or peripherally) varied based on center criteria and were at the discretion of the intensive care practitioner and surgeon. Subjects were excluded from the study if their form of support was other than VA-ECMO and only included those patients on VA-ECMO. In those patients that required more than one ECMO run, runs were combined. The ELSO database provided a patient identification (ID) and a run ID; the run IDs for the individual patient who had more than one run were combined and results were reported collectively on the individual patient.

\section{Definitions for underlying etiologies}

The primary indication for VA-ECMO was reviewed by a pediatric cardiologist (RRT) and a critical care fellow (SB) and included: 1) pulmonary; 2) cardiac; and 3) emergency ECMO extracorporeal cardiopulmonary resuscitation (ECPR). Etiologies were further subdivided into the following categories: 1) acyanotic cardiac lesions; 2) cyanotic cardiac lesions; 3) pulmonary structural lesions, including congenital diaphragmatic hernia; 4) pulmonary lesions including persistent pulmonary hypertension of the newborn (PPHN); 5) cardiac failure and/or shock; 6) pulmonary failure including respiratory distress syndrome; 7) infectious etiologies; 8) 
pulmonary lesions resulting from aspiration; 9) other cardiac lesions; 10) other pulmonary lesions; and 11) lesions otherwise not categorized.

Acyanotic and cyanotic congenital cardiac heart disease (CHD) diagnoses were grouped and coded. Each patient was reviewed by a pediatric cardiologist (RRT) to ensure appropriate coding. These diagnoses were then sorted into one of three groups according to their dominant effect on cardiovascular physiology. Category 1 (acyanotic) included defects that primarily compromised systemic output (critical aortic stenosis, coarctation of the aorta, hypoplastic left heart syndrome (HLHS), and interrupted aortic arch). Category 2 was comprised of defects that create significant and sustained cyanosis (transposition of the great vessels, tetralogy of Fallot, critical pulmonary stenosis, pulmonary atresia, tricuspid atresia, and total anomalous pulmonary venous return). For those with dual diagnoses that would place them in multiple categories, a hierarchy was used to sort them into the most appropriate category based on physiology.

\section{Definitions for variables}

Demographic, pre-ECMO support type, ECMO procedures and complications, patient complications, and outcomes were analyzed. Given the numerous pre-ECMO support types, these were reviewed by a pediatric cardiologist (RRT) and critical care fellow (SB) and were grouped into 5 categories. Category 1 contained pulmonary vasodilators and included inhaled nitric oxide (iNo) and sildenafil. Category 2 contained medications whose mechanism of action was characterized by inotropic support; these included dopamine, dobutamine, vasopressin, epinephrine, and norepinephrine. Category 3 was characterized as adjuncts to care and included the following: tris(hydroxymethyl) aminomethane (THAM), bicarbonate, systemic hypothermia, systemic steroids, inhaled anesthetics, narcotics, paralysis, plasmapheresis, and abdominal compression. Category 4 was characterized by additional ventilator support and included the use of high-frequency oscillatory ventilation (HFOV), the use of surfactant and hyperventilation. Category 5 was characterized by additional cardiac support and included such entities as bypass, the use of a pacemaker or intra-aortic balloon, and the use of the Berlin Heart.

Complications were delineated by coding from the ELSO registry and were divided into broad and specific complications. Broad categories included complications affecting these systems: neurological, pulmonary, cardiac, renal, hemorrhagic, infectious, metabolic, and complications related to mechanical issues and specific pumps used. A full listing of all the individual complications with associated ELSO codes is seen in an appendix table.

\section{Statistical analysis}

Patient and procedural characteristics, pre-ECMO support variables, and overall complications were compared with infants who died in-hospital versus those who did not. Categorical variables were summarized as a number (percent) and compared using Fisher's exact test; continuous variables were summarized as median (range) and compared with the Wilcoxon rank sum test. Variables significant at the 0.10 level in univariate analysis were considered for inclusion in a multivariable logistic regression model; $\mathrm{p}<0.05$ was required for inclusion in the final model. Analyses were performed using Stata 12.1 (StataCorp, College Station, TX).

\section{Results}

\section{Demographics}

Records of 662 eligible patients were reviewed. Males comprised approximately $55 \%$ percent of this patient population versus approximately $45 \%$ females. There was a distribution of the ages of the eligible patients; 465 (70\%) were neonates or persons less than the age of 30 days, 


\section{Cureus}

whereas 197 (30\%) were infants, or those patients who were older than 30 days. The median age at cannulation was seven days (range: 0 days-365 days) and was not significantly different between the groups. Median weight at cannulation of those who died was $3.3 \mathrm{~kg}$ (range: 1.5 $10.0 \mathrm{~kg}$ ) versus 3.5 (range: $1.9-10.9 \mathrm{~kg}$ ) who survived to discharge $(\mathrm{p}<0.001)$. Three hundred and seventy-nine (57\%) patients were cannulated via a carotid artery and internal jugular vein approach. Of the 662 eligible patients, 18 (3\%) patients had two runs while four patients had three (1\%) runs.

\begin{tabular}{|c|c|c|c|c|}
\hline In-Hospital Mortality & Total & Yes & No & P-Value \\
\hline Characteristics & & $\mathrm{n}=303(\%)$ & $\mathrm{n}=359(\%)$ & \\
\hline Sex & & & & 0.53 \\
\hline Male & $368(56)$ & $166(55)$ & $202(58)$ & \\
\hline Female & $285(43)$ & $136(45)$ & $149(42)$ & \\
\hline Weight & 3.3 & 3.2 & 3.5 & $<0.001$ \\
\hline \multicolumn{5}{|l|}{ Intormation on proceaures } \\
\hline Support type & & & & $<0.001$ \\
\hline Pulmonary & $293(44)$ & $114(38)$ & $179(50)$ & \\
\hline Cardiac & $278(42)$ & $134(44)$ & $144(40)$ & \\
\hline ECPR & $91(14)$ & $55(18)$ & $36(10)$ & \\
\hline Hours on ECMO $(n=659)$ & 132 & 162 & 118 & 0.002 \\
\hline Any procedure pre-ECLS & 375 (57) & $177(58)$ & $198(55)$ & 0.43 \\
\hline Any procedure during ECLS & $144(22)$ & $72(24)$ & $72(20)$ & 0.26 \\
\hline Any procedure post-ECLS & $38(6)$ & $11(4)$ & $27(8)$ & 0.04 \\
\hline Any cardiac procedure pre-ECLS & $155(23)$ & $72(24)$ & $83(23)$ & 0.85 \\
\hline Any cardiac procedure during ECLS & $36(5)$ & $17(6)$ & $19(5)$ & 0.87 \\
\hline Any cardiac procedure post-ECLS & $10(2)$ & $4(1)$ & $6(2)$ & 0.76 \\
\hline Hours admission to ECMO $(n=636)$ & 41 & 59 & 29 & 0.01 \\
\hline Hours intubation to ECMO $(n=625)$ & 26 & 26 & 26 & 0.59 \\
\hline
\end{tabular}

\section{TABLE 1: Baseline characteristics of the cohort}

Kg: kilograms; Support type: Reason for initiation of support; VA-ECMO: Venoarterial extracorporeal membrane oxygenation; ECPR/ECLS: emergency cardiopulmonary

\section{Univariate analysis}




\section{Cureus}

Information on ECMO, the influence of duration of ECMO, as well as the influence of any procedures performed in relation to ECLS, was also seen in Table 1. There was a significant difference in ECMO support type $(\mathrm{p}<0.001)$ at baseline. There was a predominance of cardiac ECMO support type in those who died versus those who survived; in those that survived, there was a predominance of pulmonary ECMO support type. Those who spent a longer median time on ECMO had a higher associated mortality $(\mathrm{p}<0.002)$. There were no statistically significant differences found in regards to procedures on ECLS or concerning cardiac procedures.

Pre-ECMO support also influenced in-hospital mortality. The use of pulmonary vasodilators including iNO and sildenafil, as well as additional ventilator support in the forms of HFOV, surfactant use, and a degree of hyperventilation appeared to be protective. For example, 63\% of those who survived utilized pulmonary vasodilators, whereas only $50 \%$ of those who had died had been exposed to vasodilators as part of their pre-ECMO support regimen $(p<0.001)$. Fortythree percent of those who survived utilized additional pulmonary regimens, although only approximately $30 \%$ of those who died had initiated HFOV and/or surfactant $(\mathrm{p}<0.001)$. Additional adjuncts, inotropes, and additional cardiac support did not confer significantly increased odds of mortality in this cohort.

\begin{tabular}{|c|c|c|c|}
\hline In-Hospital Mortality & $\begin{array}{l}\text { Yes } \\
\mathrm{N}=303(\%)\end{array}$ & $\begin{array}{l}\text { No } \\
N=359(\%)\end{array}$ & P-Value \\
\hline \multicolumn{4}{|l|}{ Pre-VA ECMO support } \\
\hline Pulmonary vasodilators & $150(50)$ & $226(63)$ & $<0.001$ \\
\hline Inotropic support & $256(84)$ & $314(87)$ & 0.31 \\
\hline Adjuncts & $230(76)$ & $273(76)$ & 1.0 \\
\hline Additional ventilator support & $90(30)$ & $156(43)$ & $<0.001$ \\
\hline Additional cardiac support & $128(42)$ & $131(36)$ & 0.15 \\
\hline
\end{tabular}

TABLE 2: Pre-VA-ECMO support characteristics and mortality

In-hospital mortality occurred in 303 (46\%) of this cohort of patients. The influence of complications, associated morbidities, and in-hospital mortality is seen in Table 3. Ninety-two percent of those who died had experienced a complication $(\mathrm{p}<0.001)$. Complications ranged from neurological, pulmonary, cardiac, renal, hemorrhagic, infectious, metabolic, and complications related to mechanical issues. Neurological complications in the entire cohort included 66 (10\%) hemorrhagic cerebral vascular accidents, 32 (5\%) ischemic cerebral strokes, and brain death in 10 (2\%) patients. The most common hemorrhagic complications included surgical site bleeding in 116 (18\%) patients, cannula site bleeding in 82 (12\%) patients, and disseminated intravascular coagulopathy in 42 (6\%) patients. Gastrointestinal (GI) hemorrhage occurred in 12 (2\%) patients. Hemofiltration, as part of the management schema, was also more prevalent in those who died than those who survived ( $\mathrm{p}<0.001)$ as seen in Table 3 . Renal complications, as defined by a serum creatinine level, included 34 (5\%) patients with a serum creatinine ( $\mathrm{sCr}$ ) of between $1.5-3.0 \mathrm{mg} / \mathrm{dl}$ versus 18 (3\%) patients with a $\mathrm{sCr}$ of $>3.0 \mathrm{mg} / \mathrm{dl}$. The majority of cardiac complications in the entire cohort included persistent hypertension requiring medications in 80 (12\%) patients, whereas pulmonary complications were evenly distributed between pneumothorax requiring treatment in 33 (5\%) patients and pulmonary 


\section{Cureus}

hemorrhage in 35 (5\%) patients. Infection complications included 38 (6\%) culture-proven infections while a white blood count (WBC) of less than 1,500 was seen in three $(<1 \%)$ patients. Metabolic complications included primarily hyperglycemia, as pre-defined by a serum blood glucose of $x>240 \mathrm{mg} / \mathrm{dl}$ in $56(8 \%)$ of the patient population.

In-Hospital Mortality

\section{Complications}

Any complication

Mechanical

Hemorrhagic

Neurological

Cardiac

Pulmonary

Infections

Metabolic

Non-hemofiltration renal complication

Serum creatinine

$$
<1.5
$$

$1.5-3.0$

$>3.0$

Serum creatinine $>1.5$

Hemofiltration

Dialysis
Yes

$\mathrm{n}=303(\%)$

279 (92)

117 (39)

$143(47)$

92 (30)

191 (63)

42 (14)

27 9)

75 (25)

50 (17)

$266(88)$

$28(9)$

$9(3)$

37 (12)

$91(30)$

$23(8)$
No

$\mathrm{n}=359(\%)$

P-Value

$274(76)$

$<0.001$

0.02

$<0.001$

$<0.001$

$<0.001$

$<0.001$

0.005

$13(4)$

0.03

$<0.001$

$<0.001$

$345(96)$

$5(1)$

9 (3)

$14(4)$

$<0.001$

$<0.001$

$<0.001$

TABLE 3: Complications and in-hospital mortality

Mechanical complications were seen in 223 (34\%) patients within this entire cohort. The most common mechanical complications included clots seen in the oxygenator ( $n=111 / 662,17 \%)$, as well as mechanical failure $(n=31 / 662,5 \%)$ of the entire cohort. There was not an increased mortality seen in comparing one pump versus the other in this patient cohort; however, the centrifugal pumps appeared to have a slightly higher rate of hemorrhagic hemolysis on univariate analysis (13\% versus $7 \%, \mathrm{p}=0.02)$. A listing of all respective ELSO complication codes is included. 


\section{Cureus}

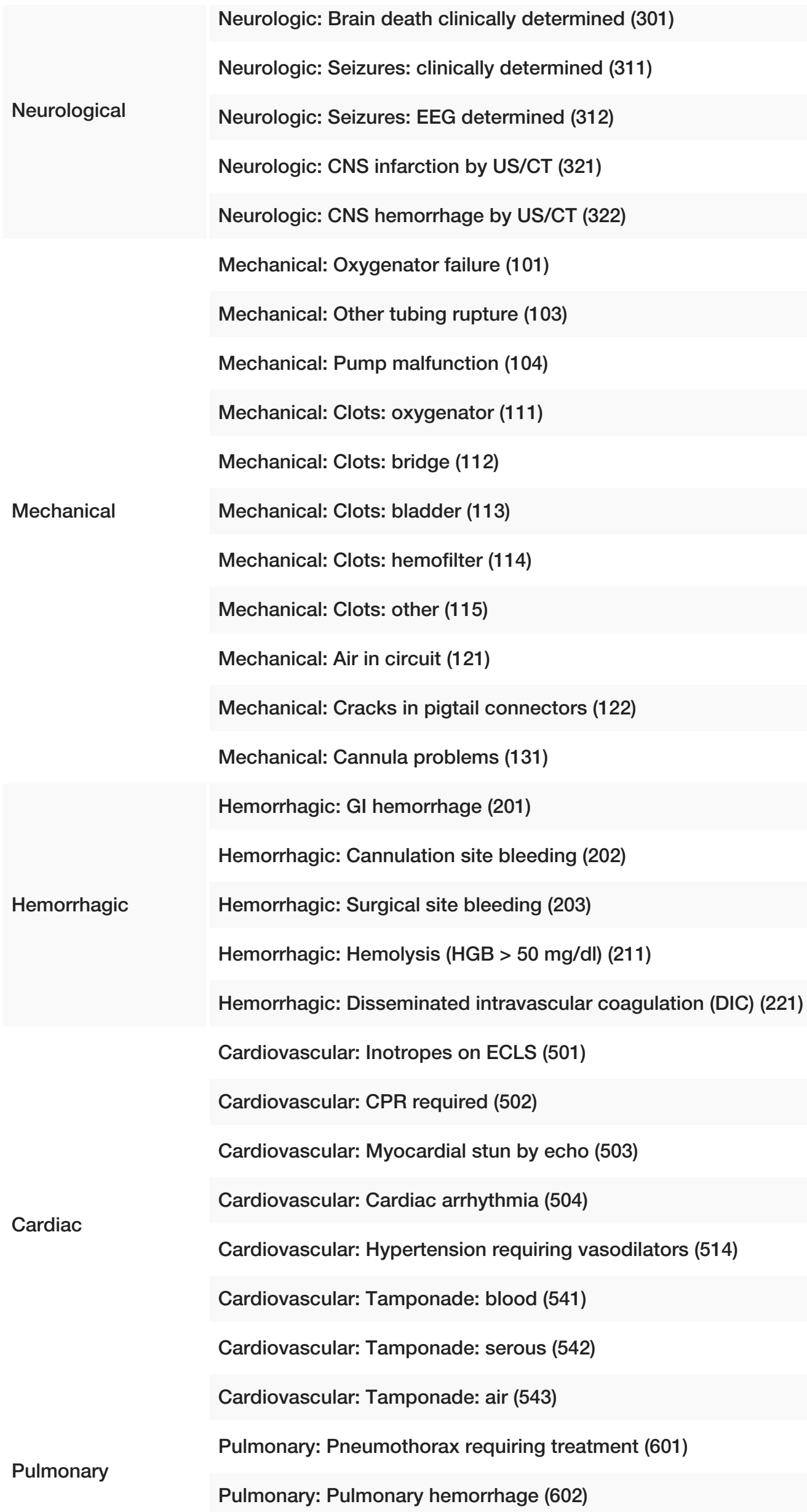




\section{Cureus}

\begin{tabular}{|l|l|}
\hline Renal: Creatinine $1.5-3.0(401)$ \\
Renal: Creatinine $>3.0(402)$ \\
Renal: Dialysis required (411) \\
Renal: Hemofiltration required (412) \\
Renal: CAVHD required (414) \\
Infectious: Culture proven infection (701) \\
Infectious: WBC < 1,500 (711) \\
Metabolic: Glucose $<40(801)$ \\
Metabolic: Glucose $>240(802)$ \\
Metabolic \\
Metabolic: Hyperbilirubinemia $(>2$ direct or $>15$ total) $(821)$
\end{tabular}

\section{TABLE 4: ELSO codes for complications}

\section{Multivariate analysis}

Congenital diaphragmatic hernia $(\mathrm{CDH})(\mathrm{OR}=3.83$, 95\% CI 1.96-7.49, $\mathrm{p}<0.001)$, cardiac failure with associated shock $(\mathrm{OR}=2.90,95 \% \mathrm{CI} 1.46-5.77, \mathrm{p}=0.002)$, and pulmonary failure, including respiratory distress syndrome $(\mathrm{OR}=4.06,95 \% \mathrm{CI} 1.72-9.58, \mathrm{p}=0.001)$ patients had the highest odds of in-hospital mortality. Birth weight of $<3 \mathrm{~kg}$ (OR=1.83, 95\% CI 1.21-2.78, p=0.004), ECPR/extracorporeal life support (ELS) (OR=3.35, 95\% CI 1.57-7.15, $\mathrm{p}=0.002)$, hemofiltration $(\mathrm{OR}=2.04,95 \% \mathrm{CI} 1.32-3.16, \mathrm{p}=0.001)$, and dialysis $(\mathrm{OR}=6.13,95 \% \mathrm{CI} 1.70-22.1, \mathrm{p}<0.001)$ were also all independent predictors of mortality. The presence of either pulmonary and/or neurological complications remained significantly associated with mortality; however, hemorrhagic, metabolic, and infectious complications, as well as type of pump, were no longer significant on multivariate analysis. Receiver operating curve (ROC) was 0.778 for the full model. 


\section{Cureus}

\begin{tabular}{|c|c|c|c|}
\hline Clinical Variables & Odds Ratio & $95 \% \mathrm{Cl}$ & P-Value \\
\hline Weight $<3 \mathrm{~kg}$ & 1.83 & $(1.21,2.78)$ & 0.004 \\
\hline \multicolumn{4}{|l|}{ Support type } \\
\hline Pulmonary & 1.00 & -- & -- \\
\hline Cardiac & 2.27 & $(1.21,4.27)$ & 0.01 \\
\hline E-CPR & 3.35 & $(1.57,7.15)$ & 0.002 \\
\hline Hour on ECMO ( $\uparrow 10$ hr.) & 1.02 & $(1.01,1.04)$ & $<0.001$ \\
\hline Pulmonary vasodilators pre-ECMO & 0.55 & $(0.36,0.85)$ & 0.007 \\
\hline Any hemorrhagic complication & 1.45 & $(0.99,2.13)$ & 0.05 \\
\hline Any neurological complication & 2.81 & $(1.77,4.45)$ & $<0.001$ \\
\hline Any pulmonary complication & 2.52 & $(1.27,4.99)$ & 0.008 \\
\hline Hemofiltration & 2.04 & $(1.32,3.16)$ & 0.001 \\
\hline Dialysis & 6.13 & $(1.70,22.1)$ & 0.006 \\
\hline \multicolumn{4}{|l|}{ Diagnosis } \\
\hline Cyanotic & 1.68 & $(1.01,2.80)$ & 0.05 \\
\hline $\mathrm{CDH} /$ diaphragm & 3.83 & $(1.96,7.49)$ & $<0.001$ \\
\hline Cardiac failure & 2.90 & $(1.46,5.77)$ & 0.002 \\
\hline Pulmonary failure & 4.06 & $(1.72,9.58)$ & 0.001 \\
\hline Infectious & 2.91 & $(1.32,6.40)$ & 0.008 \\
\hline Other & 1.00 & -- & -- \\
\hline
\end{tabular}

\section{TABLE 5: Multivariate analyses and in-hospital mortality}

Kg: kilograms; Support type: Reason for initiation of support; VA-ECMO: Venoarterial extracorporeal membrane oxygenation; ECPR/ECLS: emergency cardiopulmonary; CDH: Congenital Diaphragmatic Hernia

\section{Discussion}

During this one-year study period, we abstracted data from the ELSO registry, which included data on ECMO procedures performed on 662 eligible patients. This is collected from patients admitted to over 170 centers participating voluntarily in the registry and allows for the recording of factors predicting morbidity and mortality. Although the ELSO registry is a robust tool for the investigation of ECMO, its use does have some limitations and data cannot be construed to suggest causality. The ELSO dataset does not include specific dates for interventions and/or indications for therapy; however, given the relative sample size, these data show a robust and wide array of morbidity and mortality experienced by this particular 
cohort of infants on VA-ECMO.

Patient selection, timing of the application of ECMO and mode of ECMO continue to be important factors in predicting eventual outcomes in these cohorts of patients [10]. VA-ECMO, unlike VV- ECMO, results in mixture of pulsatile and non-pulsatile blood flow and may exquisitely alter blood flow patterns to the cerebrum, pulmonary vasculature, and renal vasculature; not appreciated as much in VV-ECMO as there is less competition with native blood flow [11]. Overall, our in-hospital mortality $46 \%$ which is similar to previously reported mortality rates seen in all ECMO cases [12]. Previously reported studies suggested that VAECMO and VV-ECMO have similar mortality rates, as well as distribution of complications to the central nervous system [13]; however, more recent studies have suggested that with improved technological advances, VV-ECMO may provide a survival advantage to certain populations [14-18]. Further larger studies are needed to delineate this and may provide a suitable alternative in those patients who do not require cardiac support.

One fact that remains is that over the past four decades the application and technology behind ECMO have changed dramatically in the face of a potentially sicker overall cohort of patients [19]. Advancements have included changes to the cannula, pumps, oxygenators, circuit configuration, and use of anticoagulation [14]. For example, according to the ELSO 2011 survey, the use of silicone membrane oxygenators continues to decline, the use of centrifugal pumps continues to increase and ECMO personnel continues to be comprised of multidisciplinary teams [20]. With those changes in technology and essentially stable mortality rates, there have been additional concerns around certain modalities. According to Thiagarajan, et al. (2013), there appeared to be an increased odd of complications related to centrifugal pumps [21]. While we did not see an overall increased mortality and percentage of complications in our patients who were exposed to centrifugal pumps, with the exception of hemorrhagic hemolysis, continued research is needed.

The events leading to cannulation are often the most important factors related to mortality and morbidity cited in VA-ECMO studies; for example, some studies have suggested that the presence of E-CPR, irrespective of the underlying diagnosis, carries a much higher mortality rate and associated morbidities [22]. In our cohort of infants, the underlying diagnosis did still play a role in the overall mortality. Those patients with congenital diaphragmatic hernias $(\mathrm{CDH})$, pulmonary failure including respiratory distress syndrome, and cardiac failure with associated shock having the highest odds of in-hospital mortality. According to a recent Cochrane review (2010), their meta-analysis on ECMO showed a potential survival benefit in four trials consisting of mature infants with severe, but potentially reversible respiratory failure [23]. All four studies showed a clear survival benefit when excluding patients with a diagnosis of $\mathrm{CDH}$. The only sub-cohort whose evidence was not as clear-cut for a survival benefit were CDH patients [23]. This is similar to other studies that have stated that optimal treatment for respiratory distress, persistent pulmonary hypertension, and pulmonary hypoplasia with associated vasculature hypoplasia (CDH) remains to be defined [24-26]. Congruently, our patients with a diagnosis of $\mathrm{CDH}$ and pulmonary failure including respiratory distress syndrome had the highest odds of mortality despite advances in technology and intensive care. Thiagarajan, et al. (2007) also reported that E-CPR saved approximately $48 \%$ who would have otherwise died [27]. Their study also showed that those neonates with both underlying cardiac and respiratory failure performed better than their counterparts with pediatric respiratory failure [27]. Juxtaposed to their study, we did not find this same association; those where E-CPR was utilized, as well as those patients with pulmonary failure and cardiac failure, had the highest odds of in-hospital mortality.

In addition to mortality and the effect of underlying etiologies, we did observe a wide array of morbidities incurred in this cohort; albeit, the timing of these comorbidities in relation to cannulation to VA-ECMO is not able to be determined from this registry data. There was a 
predominance of renal-related morbidities, including the use of hemofiltration and dialysis as being independently associated with mortality. These results are similar to results from Askenazi, et al. (2011) who have reported on the relationship between the role of fluid overload and acute kidney injury as independent predictors of morbidity and mortality in cohorts of patients primarily on VA-ECMO [9]. Acute kidney injury (AKI) may be an independent marker of mortality in of itself [28-32]; however, in our cohort, this association did not remain significant in multivariate analysis. Yet, this lack of association must be tempered by the following: serum creatinine is often not the optimum or best measure to detect AKI or predict which patients will progress to fulminant kidney failure requiring renal supportive therapy [33]. The other confounder present is that indications for renal supportive therapy (RST) during ECMO are varied and need to be standardized in both clinical practice and semantics [34]. For example, it is unclear whether the data from each center represents true convection methods for RST (hemofiltration (HF), hemodiafiltration (HDF), ultrafiltration (UF)) or if there is some overlap between aforementioned entities and hemodialysis.

As inferred by other contemporary studies, complications occurring following the institution of VA-ECMO also incur an increased mortality [14, 35-36]. Therefore, it is not surprising that $92 \%$ of those who died in our study had experienced only one type of complication ( $\mathrm{p}<0.001)$ and that, along with renal complications, there was also an increased mortality associated with neurological sequelae given the physiological effects of VA-ECMO [37]. Interestingly enough, inotropes and cardiac adjuncts did not portend increased risk of mortality in this specific cohort of patients as it has in previous studies [38]. We also found that more aggressive ventilatory support, in the form of HFOV and the use of surfactants, as well as vasodilators precannulation appeared to have an impact on mortality; however, this must be tempered as there is a wide variety of clinical results and center practices as it relates to pre-ECMO support [19, 39-46].

\section{Conclusions}

We conclude that this cohort of infants experienced diverse systemic sequelae and their mortality is high (46\%). Predicting morbidity and mortality in these complex patients is a constant challenge for the treatment team and is often used to assist in the counseling of their families in continuing such therapies. Adjunctive measures may need to be tempered or tailored to individual patients based on their underlying diagnosis and projected overall outcomes.

\section{Appendices}

\section{Additional Information \\ Disclosures}

Human subjects: Consent was obtained by all participants in this study. Boston Children's Institutional Review Board issued approval IRBP00010390. In manuscript. Animal subjects: All authors have confirmed that this study did not involve animal subjects or tissue. Conflicts of interest: In compliance with the ICMJE uniform disclosure form, all authors declare the following: Payment/services info: All authors have declared that no financial support was received from any organization for the submitted work. Financial relationships: All authors have declared that they have no financial relationships at present or within the previous three years with any organizations that might have an interest in the submitted work. Other relationships: All authors have declared that there are no other relationships or activities that could appear to have influenced the submitted work. 


\section{Acknowledgements}

The authors wish to thank both Chueh (Julia) Lien who has provided superb assistance in our data collection process. The authors of this would also like to thank the Respiratory Therapist/Extracorporeal Membrane Oxygenation (ECMO) Support Staff for their assistance in our overall data collection and care of these types of patients as well.

\section{References}

1. Paden ML, Rycus PT, Thiagarajan RR, ELSO Registry: Update and outcomes in extracorporeal life support. Semin Perinatol. 2014, 38:65-70. 10.1053/j.semperi.2013.11.002

2. Paden ML, Conrad SA, Rycus PT, Thiagarajan RR, ELSO Registry: Extracorporeal Life Support Organization Registry Report 2012. ASAIO J. 2013, 59:202-10. 10.1097/MAT.0b013e3182904a52

3. Lequier L: Extracorporeal life support in pediatric and neonatal critical care: a review. J Intensive Care Med. 2004, 19:243-58.

4. Chung M, Shiloh AL, Carlese A: Monitoring of the Adult Patient on Venoarterial Extracorporeal Membrane Oxygenation. ScientificWorldJournal. 2014, 2014:393258. 10.1155/2014/393258

5. Askenazi DJ, Selewski DT, Paden ML, Cooper DS, Bridges BC, Zappitelli M, Fleming GM: Renal replacement therapy in critically ill patients receiving extracorporeal membrane oxygenation. Clin J Am Soc Nephrol. 2012, 7:1328-36. 10.2215/CJN.12731211

6. Blijdorp K, Cransberg K, Wildschut ED, Gischler SJ, Jan Houmes R, Wolff ED, Tibboel D: Haemofiltration in newborns treated with extracorporeal membrane oxygenation: a casecomparison study. Crit Care. 2009, 13:R48. 10.1186/cc7771

7. Gupta P, McDonald R, Chapman CW, Stroud M, Gossett JM, Imamura M, Bhutta AT: 20-year experience of prolonged extracorporeal membrane oxygenation in critically ill children with cardiac or pulmonary failure. Ann Thorac Surg. 2012, 93:1584-90.

10.1016/j.athoracsur.2012.01.008

8. Selewski DT, Cornell TT, Blatt NB, Han YY, Mottes T, Kommareddi M, Gaies MG, Annich GM, Kershaw DB, Shanley TP, Heung M: Fluid overload and fluid removal in pediatric patients on extracorporeal membrane oxygenation requiring continuous renal replacement therapy. Crit Care Med. 2012 , 40:2694-2699. 10.1097/CCM.0b013e318258ff01

9. Askenazi DJ, Ambalavanan N, Hamilton K, Cutter G, Laney D, Kaslow R, Georgeson K, Barnhart DC, Dimmitt RA: Acute kidney injury and renal replacement therapy independently predict mortality in neonatal and pediatric noncardiac patients on extracorporeal membrane oxygenation. Pediatr Crit Care Med. 2011, 12:e1-6. 10.1097/PCC.0b013e3181d8e348

10. Hayes D Jr, Tobias JD, Kukreja J, Preston TJ, Yates AR, Kirkby S, Whitson BA: Extracorporeal life support for acute respiratory distress syndromes. Ann Thorac Med. 2013, 8:133-141. 10.4103/1817-1737.114290

11. Hansell DR: Extracorporeal membrane oxygenation for perinatal and pediatric patients. Respir Care. 2003, 48:352-62.

12. Dalton HJ, Rycus PT, Conrad SA: Update on extracorporeal life support 2004. Semin Perinatol. 2005, 29:24-33. 10.1053/j.semperi.2005.02.005

13. Zahraa JN, Moler FW, Annich GM, Maxvold NJ, Bartlett RH, Custer JR: Venovenous versus venoarterial extracorporeal life support for pediatric respiratory failure: are there differences in survival and acute complications?. Crit Care Med. 2000, 28:521-5. 10.1097/00003246200002000-00039

14. Maslach-Hubbard A, Bratton SL: Extracorporeal membrane oxygenation for pediatric respiratory failure: History, development and current status. World J Crit Care Med. 2013, 2:29-39. 10.5492/wjccm.v2.i4.29

15. Delius R, Anderson H 3rd, Schumacher R, Shapiro M, Otsu T, Toft K, Hirsch J, Bartlett R: Venovenous compares favorably with venoarterial access for extracorporeal membrane oxygenation in neonatal respiratory failure. J Thorac Cardiovasc Surg. 1993, 106:329-38.

16. Rollins MD, Hubbard A, Zabrocki L, Barnhart DC, Bratton SL: Extracorporeal membrane oxygenation cannulation trends for pediatric respiratory failure and central nervous system injury. J Pediatr Surg. 2012, 47:68-75. 10.1016/j.jpedsurg.2011.10.017

17. Knight GR, Dudell GG, Evans ML, Grimm PS: A comparison of venovenous and venoarterial 
extracorporeal membrane oxygenation in the treatment of neonatal respiratory failure. Crit Care Med. 1996, 24:1678-83. 10.1097/00003246-199610000-00013

18. Skinner SC, Iocono JA, Ballard HO, Turner MD, Ward AN, Davenport DL, Paden ML, Zwischenberger JB: Improved survival in venovenous vs venoarterial extracorporeal membrane oxygenation for pediatric noncardiac sepsis patients: a study of the Extracorporeal Life Support Organization registry. J Pediatr Surg. 2012, 47:63-7. 10.1016/j.jpedsurg.2011.10.018

19. Langham M Jr, Kays DW, Beierle EA, Chen MK, Stringfellow K: Expanded Application of Extracorporeal Membrane Oxygenation in a Pediatric Surgery Practice. Ann Surg. 2003, 237:766-774. 10.1097/01.SLA.0000067740.05989.45

20. Lawson S, Ellis C, Butler K, McRobb C, Mejak B: Neonatal extracorporeal membrane oxygenation devices, techniques and team roles: 2011 survey results of the United States' Extracorporeal Life Support Organization centers. J Extra Corpor Technol. 2011, 43:236-244.

21. Barrett CS, Jaggers JJ, Cook EF, Graham DA, Yarlagadda VV, Teele SA, Almond CA, Bratton SL, Seeger JD, Dalton HJ, Rycus PT, Laussen P, Thiagarajan RR: Pediatric ECMO Outcomes: Comparison of Centrifugal Versus Roller Blood Pumps Using Propensity Score Matching. ASAIO J. 2013, 59:145-51. 10.1097/MAT.0b013e31828387cd

22. Aubron C, Cheng AC, Pilcher D, Leong T, Magrin G, Cooper DI, Scheinkestel C, Pellegrino V: Factors associated with outcomes of patients on extracorporeal membrane oxygenation support: a 5-year cohort study. Crit Care. 2013, 17:R73. 10.1186/cc12681

23. Mugford M, Elbourne D, Field D. Extracorporeal: Extracorporeal membrane oxygenation for severe respiratory failure in newborn infants. Cochrane Database Syst Rev. 2008, Issue 3:CD001340. 10.1002/14651858.CD001340.pub2

24. Kays DW, Langham MR Jr, Ledbetter DJ, Talbert JL: Detrimental effects of standard medical therapy in congenital diaphragmatic hernia. Ann Surg. 1999, 230:340-8. 10.1097/00000658199909000-00007

25. Schwartz IP, Bernbaum JC, Rychik J, Grunstein M, D'Agostino J, Polin RA: Pulmonary hypertension in children following extracorporeal membrane oxygenation therapy and repair of congenital diaphragmatic hernia. J Perinatol. 1999, 19:220-6. 10.1038/sj.jp.7200141

26. Dela Cruz TV, Stewart DL, Robinson TW, Bond SJ: The use of a second course of extracorporeal membrane oxygenation in neonatal patients. ASAIO J. 1996, 42:230-32.

27. Thiagarajan R, Laussen RC, Rycus R, Bartlett RH, Bratton SL: Extracorporeal Membrane oxygenation to aid in cardiopulmonary resuscitation in infants and children. Circulation. 2007, 116:1693-1700. 10.1161/CIRCULATIONAHA.106.680678

28. Weber TR, Connors RH, Tracy TF Jr, Bailey PV, Stephens C, Keenan W: Prognostic determinants in extracorporeal membrane oxygenation for respiratory failure in newborns. Ann Thorac Surg. 1990, 50:720-723. 10.1016/0003-4975(90)90669-W

29. Smith AH, Hardison DC, Worden CR: Acute renal failure during extracorporeal support in the pediatric cardiac patient. ASAIO J. 2009, 55:412-16. 10.1097/MAT.0b013e31819ca3d0

30. Swaniker F, Kolla S, Moler F: Extracorporeal life support outcome for 128 patients with respiratory failure. J Pediatr Surg. 2000, 35:197-202. 10.1016/S0022-3468(00)90009-5

31. Zwiers AJ, de Wildt SN, Hop WC, Dorresteijn EM, Gischler SJ, Tibboel D, Cransberg K: Acute kidney injury is a frequent complication in critically ill neonates receiving extracorporeal membrane oxygenation: a 14-year cohort study. Crit Care. 2013, 17:R151. 10.1186/cc12830

32. Wolf MJ, Chanani NK, Heard ML, Kanter KR, Mahle WT: Early renal replacement therapy during pediatric cardiac extracorporeal support increases mortality. Ann Thorac Surg. 2013, 96:917-22. 10.1016/j.athoracsur.2013.05.056

33. Zhou H, Hewitt SM, S.T. Yuen P, Star RA: Acute Kidney Injury Biomarkers - Needs, Present Status, and Future Promise. Nephrol Self Assess Program. 2006, 5:63-71.

34. Fleming GM, Askenazi DJ, Bridges BC, Cooper DS, Paden ML, Selewski DT, Zappitelli M: A multicenter international survey of renal supportive therapy during ECMO: the Kidney Intervention During Extracorporeal Membrane Oxygenation (KIDMO) group. ASAIO J. 2012, 58:407-14. 10.1097/MAT.0b013e3182579218

35. Zabrocki LA, Brogan TV, Statler KD, Poss WB, Rollins MD, Bratton SL: Extracorporeal membrane oxygenation for pediatric respiratory failure: Survival and predictors of mortality. Crit Care Med. 2011, 39:364-70. 10.1097/CCM.0b013e3181fb7b35

36. Brogan TV, Thiagarajan RR, Rycus PT, Bartlett RH, Bratton SL: Extracorporeal membrane oxygenation in adults with severe respiratory failure: a multi-center database. Intensive Care 
Med. 2009, 35:2105-14. 10.1007/s00134-009-1661-7

37. Fukuda S, Aoyama M, Yamada Y, Saitoh N, Honjoh T, Hasegawa T, Futamura M, Katoh J, Niimi N, Tanaka S, Nagaya M: Comparison of venoarterial versus venovenous access in the cerebral circulation of newborns undergoing extracorporeal membrane oxygenation. Pediatr Surg Int. 1999, 15:78-84. 10.1007/s003830050521

38. Prodhan P, Stroud M, El-Hassan N, Peeples S, Rycus P, Brogan TV, Tang X: Prolonged extracorporeal membrane oxygenator support among neonates with acute respiratory failure: a review of the extracorporeal life support organization registry. ASAIO J. 2014, 60:63-69. 10.1097/MAT.0000000000000006

39. Cornfield DN, Maynard RC, deRegnier RA, Guiang SF 3rd, Barbato JE, Milla CE: Randomized, controlled trial of low-dose inhaled nitric oxide in the treatment of term and near-term infants with respiratory failure and pulmonary hypertension. Pediatrics. 1999, 104:1089-1094. 10.1542/peds.104.5.1089

40. Finer NN, Barrington KJ: Nitric oxide for respiratory failure in infants born at or near term . Cochrane Database Syst Rev. 2001, CD000399. 10.1002/14651858.CD000399.pub2

41. Wung JT, James LS, Kilchevsky E, James E: Management of infants with severe respiratory failure and persistence of the fetal circulation, without hyperventilation. Pediatrics. 1985, 76:488-494.

42. Marks SD, Nicholl RM: The reduction in the need for ECMO by using surfactant in meconium aspiration syndrome. J Pediatr. 1999, 135:267-268.

43. Roy BJ, Rycus P, Conrad SA, Clark RH: The changing demographics of neonatal extracorporeal membrane oxygenation patients reported to the Extracorporeal Life Support Organization (ELSO) Registry. Pediatrics. 2000, 106:1334-1338. 10.1542/peds.106.6.1334

44. Hintz SR, Suttner DM, Sheehan AM, Rhine WD, Van Meurs KP: Decreased use of neonatal extracorporeal membrane oxygenation (ECMO): how new treatment modalities have affected ECMO utilization. Pediatrics. 2000, 106:1339-1343. 10.1542/peds.106.6.1339

45. Kennaugh JM, Kinsella JP, Abman SH, Hernandez JA, Moreland SG, Rosenberg AA: Impact of new treatments for neonatal pulmonary hypertension on extracorporeal membrane oxygenation use and outcome. J Perinatol. 1997, 17:366-369.

46. Domico MB, Ridout DA, Bronicki R, Anas NG, Cleary JP, Cappon J, Goldman AP, Brown KL: The impact of mechanical ventilation time before initiation of extracorporeal life support on survival in pediatric respiratory failure: a review of the Extracorporeal Life Support Registry. Pediatric Crit Care Med. 2012, 13:16-21. 10.1097/PCC.0b013e3182192c66 